\title{
Preserving the human touch in medicine in a digital age
}

\author{
Cite as: CMAJ 2019 June3;191:E622-3. doi: 10.1503/cmaj.109-5757
}

Posted on cmajnews.com on May 16, 2019.

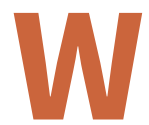

hen a doctor at the Kaiser Permanente Medical Center in Fremont, California, used a rolling video-technology "robot" to inform a patient that he was dying, the story went viral. The coldness of the delivery sparked outrage, but it also touched off a valuable debate on the importance of preserving a human presence in medicine and how to safeguard compassion in the telemedicine age.

Dr. Brett Belchetz, the CEO of Maple, a Toronto-based platform that enables virtual health care, knew the Kaiser story would lead to questions about Maple's virtual medicine pilot at Western Hospital in Prince Edward Island. The "telerounding" pilot sees a remote doctor doing daily rounds through video link to compensate for a physician shortage. Like at Kaiser, Maple operates a mobile cart that's wheeled from room to room by nurses.

"Telemedicine done right comes down to a person-to-person interaction," said Belchetz. "It's one human being talking to another, and if you talk to another human being compassionately and appropriately, it will go well. And if you don't, it won't."

In the PEI telerounding scenario, doctors maintain regular rounds so a patient is likely to see the same face on-screen for three to five days in a row. "Patients feel surprised on the first day, but by day three they say they don't notice the screen," said Belchetz. "It tends to disappear and they have the same conversation they would if the doctor was actually in the room."

He noted that there is always a nurse present to offer support and to make sure the patient understands what is being

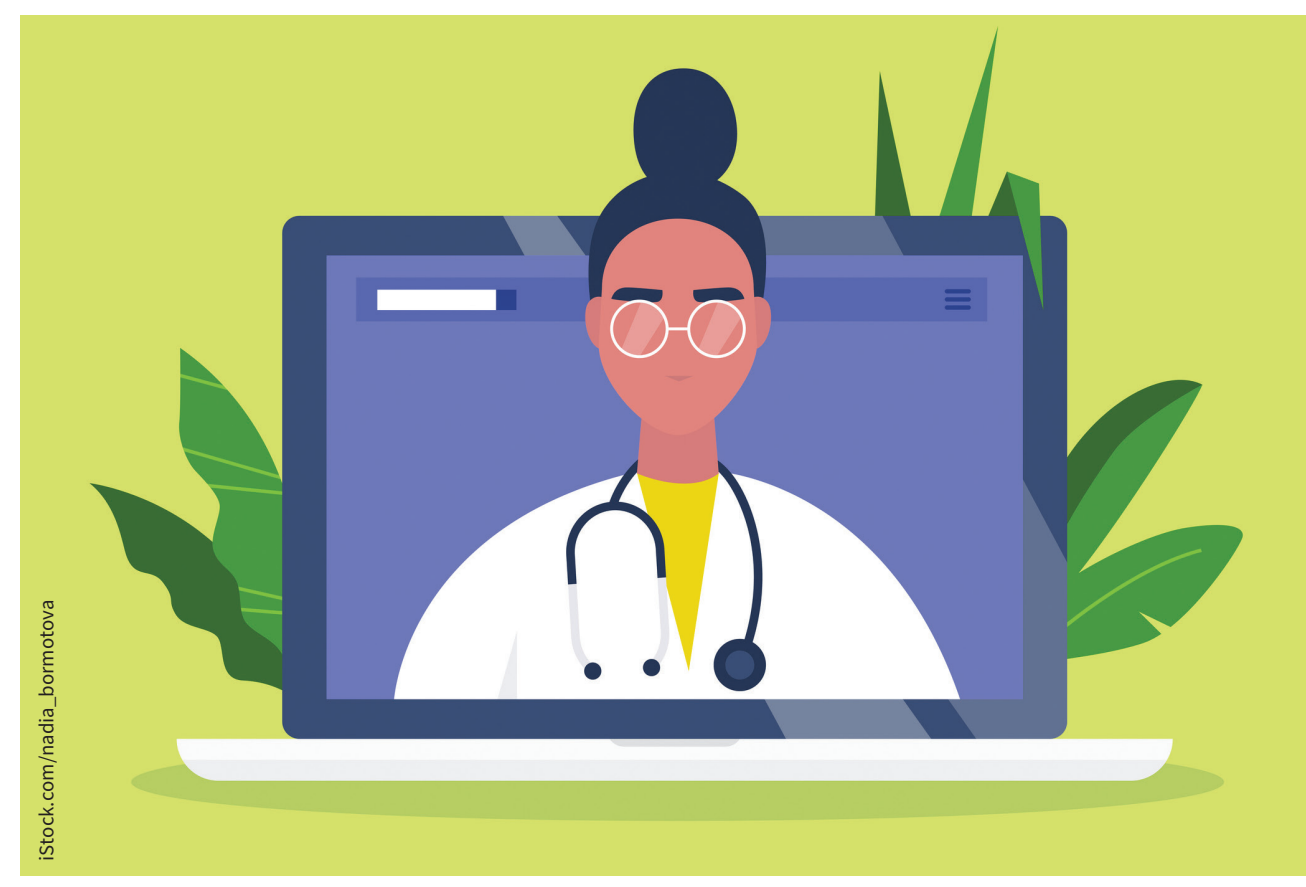

Should certain physican-patient discussions, such as the disclosure of a terminal diagnosis, ever occur virtually?

communicated. "The issue is not whether certain types of news should or shouldn't be delivered in person - it's all about how you deliver it."

Scientist Jay Shaw agrees, for the most part, but points out that the Kaiser case illustrates the importance of thinking long and hard about how technologies are used before problems arise. "Whenever a technology is used in new ways, when boundaries are pushed, that's when professional groups accidentally learn the limits of what they can and cannot do with this technology."

Shaw looks at new technologies through a wider lens in his work at the Institute for Health System Solutions and Virtual Care at the Women's College
Research Institute. He calls Kaiser's rolling "robot" a classic case of misguided design. Just as a chair encourages you to sit, a "robot" designed with human proportions encourages the user to feel like they're in the room with the patient. "It actually encourages the overstepping of the boundaries of what's acceptable in telemedicine."

Going forward, he says it will be increasingly important for health care professionals to think about how new technologies affect how they interact with patients - and if there are unintended consequences. Training programs for doctors intending to practise telemedicine should consider including more discussion on how to engage 
appropriately. "Telemedicine has been around for decades, but not enough attention has been given to best practices," said Shaw.

Best practice might include thinking deeply about whether various telemedicine technologies encourage doctors to do things they might not if they were with a person face to face. Do they encourage shortcuts? That deep reflection must be ongoing and updated as society's comfort level and interactions with these technologies continues to evolve.
"There's always room to improve," added Belchetz. "Delivering bad news has always been an art, not a science. That holds just as true whether it's a physical or virtual setting."

Sarah Brown, Ottawa, Ont. 